\title{
Association of chronic obstructive pulmonary disease and obstructive sleep apnea consequences
}

\author{
Carlos Zamarrón' \\ Vanesa García Paz' \\ Emilio Morete' \\ Felix del Campo Matías ${ }^{2}$ \\ 'Servicio de Neumología, Hospital \\ Clínico Universitario de Santiago, \\ Santiago, Spain; ${ }^{2}$ Servicio de \\ Neumologia, Hospital Universitario \\ Rio Ortega de Vallaclolid, Vallaclolid, \\ Spain
}

Correspondence: Carlos Zamarrón Servicio de Neumología, Hospital Clínico Universitario de Santiago, C/Travesia de la Choupana s/n 15706, Santiago de Compostela, Spain

$\mathrm{Tel}+34981950085$

Fax +34981950454

Email carlos.zamarron.sanz@sergas.es

\begin{abstract}
Obstructive sleep apnea syndrome (OSAS) and chronic obstructive pulmonary disease (COPD) are two diseases that often coexist within an individual. This coexistence is known as overlap syndrome and is the result of chance rather than a pathophysiological link. Although there are claims of a very high incidence of OSAS in COPD patients, recent studies report that it is similar to the general population. Overlap patients present sleep-disordered breathing associated to upper and lower airway obstruction and a reduction in respiratory drive. These patients present unique characteristics, which set them apart from either COPD or OSAS patients. COPD and OSAS are independent risk factors for cardiovascular events and their coexistence in overlap syndrome probably increases this risk. The mechanisms underlying cardiovascular risk are still unclear, but may involve systemic inflammation, endothelial dysfunction, and tonic elevation of sympathetic neural activity. The treatment of choice for overlap syndrome in stable patients is CPAP with supplemental oxygen for correction of upper airway obstructive episodes and hypoxemia during sleep.

Keywords: chronic obstructive pulmonary disease, obstructive sleep apnea syndrome, overlap syndrome, sleep, cardiovascular disease
\end{abstract}

\section{Introduction}

Chronic obstructive pulmonary disease (COPD) is a condition of progressive deterioration of the respiratory system characterized by obstruction of pulmonary airways and decreased airflow. The airflow limitation is usually progressive and associated to an abnormal inflammatory response of the lungs to noxious particles or gases, primarily caused by cigarette smoking (Celli and MacNee 2004).

COPD consists of two disorders; chronic bronchitis and emphysema. The diagnosis of chronic bronchitis applies to patients who have a chronic productive cough for at least three months of the year in two or more successive years. On the other hand, emphysema is a pathological diagnosis describing permanent abnormal enlargement of the airspaces distal to the terminal bronchioles, accompanied by destruction of alveolar walls. Most patients have elements of both chronic bronchitis and emphysema in varying degrees, but some may have one without the other (Clausen 1990). Although mainly affecting the lungs, it also produces other significant systemic consequences, including skeletal muscle dysfunction, nutritional abnormalities and weight loss, cardiovascular and nervous system abnormalities, as well as osteoskeletal effects (Andreassen and Vestbo 2003; Agusti 2005).

COPD is a major global epidemic affecting 5\%-15\% of all adults in industrialized countries (Pauwels et al 2001), normally presenting after the age of 50. Incidence increases with age, such that $50 \%$ of smokers over the age of 65 years are affected (Louw et al 1996). Using a variety of guides, Linberg and colleagues (2005) reported a prevalence of COPD between $7.6 \%$ and $12.2 \%$. In a multicenter epidemiological study carried out in Spain, COPD was found in $15.8 \%$ of men and $5.5 \%$ of women (Peña et al 2000). 
COPD is a major cause of morbidity, mortality, and disability in the United States. An estimated 10 million adults in this country were diagnosed with COPD in the year 2000 (Lindstrom et al 2002). It is becoming more common, and accounts for significant and increasing utilization of health care resources (Faulkner and Hilleman 2003; Ramsey and Sullivan 2003).

Obstructive sleep apnea syndrome (OSAS) is a common disorder characterized by recurrent upper airway collapse during sleep (Young et al 1993). The inspiratory efforts to overcome occlusion lead to arousal, sleep fragmentation, and oxyhemoglobin desaturation (Deegan and McNicholas 1995). Though clinically recognized for more than two decades (Gastaut et al 1965; Lugaresi et al 1972; Guilleminault 1985), general awareness of OSAS has been slow to develop. In a middle-aged population, Young and colleagues (1993) found that $2 \%$ of women and $4 \%$ of men presented OSAS. In our community, there is an OSAS prevalence of $3.4 \%$ in men, $3 \%$ in women (Duran et al 2001), and 6.8\% among subjects 50-70 years of age (Zamarron et al 1999).

OSAS sometimes coexists with COPD. Flenley (1985) called this combination "overlap syndrome." We analyze the epidemiology, pathophysiology, and clinical features as well as therapy for overlap syndrome.

\section{Effects of sleep on ventilation}

Human sleep can be divided into two patterns, nonrapid eye movement sleep (NREM) and rapid eye movement sleep (REM), each with distinctive physiological characteristics. The four stages of NREM sleep are categorized by the frequency and amplitude of the electroencephalography (EEG), the presence of sleep spindles and $\mathrm{K}$ complexes and electro-oculogram and electromyogram findings. REM sleep is characterized by bursts of rapid eye movement, muscle atonia and shallow and irregular breathing. REM sleep is subdivided into two periods: tonic and phasic. Longer REM periods occur mainly during the last part of nocturnal sleep.

Sleep has profound effects on ventilation (Douglas et al 1982a), which are partly attributable to a slight decrease in metabolic rate (Douglas 1985; White et al 1985). In fact, the respiratory system is challenged by sleep, and for patients debilitated by respiratory disease, the conditions imposed may become excessive and lead to failure. Furthermore, when respiratory failure is already present during wakefulness, the situation is even more serious during sleep.

We will only briefly summarize the main effects of sleep on ventilation, as comprehensive descriptions already exist (Phillipson 1978; Krimsky and Leiter 2005).
Breathing responses are distinctly different during REM and NREM sleep. There is a significant reduction in minute ventilation, especially during REM sleep, as a result of decreased tidal volume not being fully compensated by an increase in respiratory frequency (Becker et al 1999). The consequence is a worsening of arterial blood gases with a significant reduction in partial pressure of oxygen in arterial blood $\left(\mathrm{PaO}_{2}\right)$ and an increase in partial pressure of carbon dioxide in arterial blood $\left(\mathrm{PaCO}_{2}\right)$ (Calverley et al 1982). During NREM sleep, gas exchange becomes altered with a decrease is $\mathrm{PaO}_{2}$ (Muller et al 1980), but not as much as during REM sleep.

Compared to wakefulness, ventilatory response to hypercapnia and hypoxia is diminished during NREM sleep and further depressed during REM sleep (Douglas et al 1982b; Douglas 1985). The ventilatory and arousal responses to hypercapnia are much more robust than for hypoxia, with only slight changes in $\mathrm{PaCO}_{2}$ causing recognizable alterations of minute ventilation (Morrell et al 1995).

Decreased muscle tone during sleep increases respiratory resistance and the inability to compensate these changes probably contributes to reduced responses (Wiegand et al 1991). During NREM sleep, the phasic electromyographic activity of genioglossus and geniohyoid muscles is well-maintained (Basner et al 1991), but tonic activity of upper airway dilators decreases (Wiegand et al 1990; Tangel et al 1992). During REM sleep, hypotonia of postural muscles, including intercostals muscles and other accessory respiratory muscles, occurs (Millman et al 1988; Wiegand 1990), and upper airway resistance increases (Ballard et al 1995).

Lung volume is also reduced during sleep and this is manifested by a reduction in the functional residual capacity (FRC) during NREM sleep (Hudgel and Devadatta 1984). Several factors, reduction in lung compliance and reduced respiratory muscle tone, have been suggested as potential causal factors in the reduction in FRC (Bryan and Muller 1980; Ballard et al 1990). It has been hypothesized that reduced FRC during sleep may induce the closure of airways within the regular breath, causing a ventilation-perfusion mismatch, contributing to the small but yet significant changes in arterial saturation seen especially during REM sleep (Block et al 1979).

\section{Effects of sleep on ventilation in COPD patients}

The control of breathing in patients with COPD follows the same basic principles as in normal subjects; however, these patients present lower feedback response during sleep. A decrease in oxygen saturation during sleep may appear 
in normal subjects, as well as COPD patients; however, in the latter it has a much greater effects on arterial blood gases due to the different position of initial $\mathrm{PaO}_{2}$ on the $\mathrm{O}_{2}$ dissociation curve.

Nocturnal desaturation in COPD patients presents specific characteristics (Table 1). It mainly takes place at the end of the night during REM sleep (Catterall et al 1985) and events may vary considerably from one night to the next, especially in patients with moderate-to-severe COPD (Lewis et al 2003). In addition, these desaturations are significantly related to daytime hypoxemia and hypercarbia (Mulloy and McNicholas 1996); the more pronounced daytime hypoxemia and hypercapnia, the more severe nocturnal hypoxemia (Flenley 1985). Furthermore, COPD patients may require direct assessment of nocturnal desaturation by oximetry, because the degree of hypoxemia during sleep cannot be predicted from measurement of arterial oxygen saturation in individual awake patients.

The main mechanism causing nocturnal desaturations in COPD patients is periodic hypoventilation, which, in turn, is believed to be the result of decreased activity in intercostals muscles and blunted chemical respiratory drive (Tatsumi et al 1986; Heijdra et al 1995). This is especially pronounced in patients with hyperinflated lung (Berthon-Jones and Sullivan 1984). Another cause of nocturnal desaturations is the worsening of ventilation perfusion mismatching which is related to a decreased functional residual capacity and the dissociation between diaphragmatic and intercostals activity during REM sleep.

\section{Effects of sleep on ventilation in OSAS patients}

During apneas caused by obstruction, the collapsed pharynx impedes airflow in spite of continued effort to breathe. This causes progressive asphyxia, which increasingly stimulates breathing efforts against the collapsed airway, typically until the person is awakened (Wiegand and Zwillich 1994).

Table I COPD desaturation characteristics

Occurs mainly during REM sleep
Presents considerable variability in nocturnal desaturation from night to
night
Statistically relationships exist between nocturnal desaturation and daytime
hypoxemia and hypercarbia
Nocturnal desaturarion cannot be predicted from awake measurement of
arterial oxygen saturation in individual patients

Abbreviations: COPD, chronic obstructive pulmonary disease; REM, rapid eye movement sleep.
Various factors, ranging from upper airway anatomy to central respiratory control mechanisms, interact to produce the clinical syndrome of OSAS. The primary defect is probably an anatomically small or collapsible pharyngeal airway, in combination with a sleep-induced fall in upper airway muscle activity (Liistro 2002; Fogel et al 2004). One or more of these variables, which conspire to cause upper airway obstruction (Hudgel 1992; Badr 1999), may affect any given OSAS patient.

Some studies have shown that ventilatory control is less stable in patients with OSAS, (Hudgel et al 1998; Younes et al 2001), while other authors claim that ventilatory instability alone is not sufficient to produce periodic breathing (Wellman et al 2004). Upper airway resistance in OSAS appears to be influenced by the intensity of the central respiratory drive (Series et al 1989).

Abnormal hypoxic and hypercapnic respiratory drive has also been reported in hypercapnic OSAS patients, in contrast to normal hypoxic and hypercapnic respiratory drive in eucapnic patients (Garay et al 1981; Soto Campos et al 1996). The role of this reduction in chemical drives is still under discussion. It is not clear whether it is an inherited abnormality in ventilatory control (El Bayadi et al 1990; Redline et al 1997), or secondary to sleep apnea as suggested by the improvement in ventilatory response to $\mathrm{CO}_{2}$ in hypercapnic OSAS patients after CPAP therapy (Berthon-Jones and Sullivan 1987; Lin 1994). Lin studied six patients with hypercapnic OSAS and 24 patients with eucapnic OSAS. Both the slope and baseline level of ventilatory response and mouth occlusion pressure improved significantly in hypercapnic patients after two weeks of CPAP therapy (Lin 1994).

\section{Overlap syndrome Physiological consequences}

Clinical evidence suggests that the majority of patients with OSAS are eucapnic during wakefulness, and that detection of daytime hypercapnia attests to mechanical impairment of the respiratory system due to obesity and/or COPD (Guilleminault et al 1976; Leech et al 1987).

Overlap syndrome predisposes to daytime hypercapnia and hypoxemia independently of lung function (Chaouat et al 1997). Nocturnal desaturation severity is related to a specific entity within the wide spectrum of sleep-disordered breathing and the severity of COPD.

It is known that overlap patients present more nocturnal desaturation than patients with either OSAS or COPD alone (Chaouat et al 1995; Sanders et al 2003). Sanders and colleagues (2003) examined the degree to which COPD and 
OSAS independently and jointly contribute to desaturation during sleep. After adjusting for confounding factors, the odds ratio for nocturnal oxyhemoglobin desaturation was considerably increased in OSAS patients. Bednarek and colleagues (2005) compared polysomnographic variables between overlap syndrome and OSAS subjects. The overlap syndrome group had lower mean arterial blood saturation and spent more time in desaturation than the OSAS group. Radwan and colleagues (1995) compared the breathing pattern and $\mathrm{CO}_{2}$ response in 11 obese male overlap syndrome patients, 20 obese male OSAS patients with normal lung function, and 13 healthy nonobese controls. Overlap patients had a higher breathing frequency and lower tidal volume than OSAS patients. The OSAS group presented similar values to controls in ventilatory response to $\mathrm{CO}_{2}$ and occlusion pressure responses. This author concludes that overlap patients with hypercapnia have both blunted ventilatory responses and mouth occlusion pressure responses to $\mathrm{CO}_{2}$ (Radwan et al 1995) and that ventilatory response may be disturbed by lung mechanics and gas exchange. In subjects with chronic hypercapnia, there is an increased blood bicarbonate concentration, which may inhibit $\mathrm{CO}_{2}$ sensitivity and decreases mouth occlusion pressure response (Radwan et al 1995). Other authors have postulated that hyperinflation of the lung may also decrease mouth occlusion pressure response (Erbland et al 1990).

In patients with overlap syndrome, sleep disordered breathing is associated with upper and lower airway obstruction and a reduction in respiratory drive. Respiratory muscles may also fatigue which is related to the mechanical disadvantage of chest wall hyperinflation. Moreover, there is also a reduction in functional residual capacity which is related to supine posture and sleep state, and a ventilation perfusion mismatch (Figure 1).

\section{Pulmonary hemodynamics}

Pulmonary hemodynamic studies during sleep in COPD patients have been scarce probably because its invasive nature is not compatible with normal sleep (Weitzenblum and Chaouat 2004).

Alveolar hypoxia is the most important mechanism leading to pulmonary arterial vasoconstriction and pulmonary hypertension (Bonsignore et al 1994) and COPD is frequently complicated by the development of pulmonary hypertension, which is associated with increased morbidity and mortality (Chaouat et al 2005; Wright et al 2005).

OSAS patients may also present sustained pulmonary hypertension (Sanner et al 1997; Sajkov et al 1999; Bady et al 2000), and the risk increases considerably if it is associated with COPD, obesity or both (Bradley 1992; Laks et al 1995; Chaouat et al 1996).

In a group of patients with overlap syndrome, Chaouat and colleagues (1995) found that the main determinants of pulmonary hypertension were daytime arterial blood gases and $\mathrm{FEV}_{1}$. In a study by Hawrylkiewicz and colleagues (2004), pulmonary hypertension was found in $13.6 \%$ of OSAS patients (related to disease severity and obesity) and in $80 \%$ of overlap patients.

\section{Epidemiology}

Overlap syndrome has a prevalence of 14\% among patients with mild COPD (Chaouat et al 1995) and 11\% among patients with OSAS (Sanders et al 2003). The prevalence of overlap syndrome is very different depending on the definition used. Some of the apparent discrepancies between studies can be explained by differences in selection criteria, population characteristics and design (Table 2). In early studies, a high prevalence of OSAS was found in individuals with COPD. Guilleminault and colleagues (1980) studied 26 COPD patients while sleeping and found that $92 \%$ of all abnormal respiratory events during sleep contained an obstructive component. Chaouat and colleagues (1995) prospectively investigated 265 OSAS patients and reported that $11 \%$ had an obstructive spirographic pattern. Resta and colleagues (2000) retrospectively evaluated data from 213 consecutive patients referred to the Sleep Laboratory, and found that $16 \%$ had overlap syndrome. De Miguel and colleagues (2002) found a $28.5 \%$ prevalence of overlap in a group of patients referred to the hospital. However, this high prevalence could well be due to a selection bias. Nevertheless, a very large study including 5,954 participants done in conjunction with the Sleep Heart Health Study, did not find significant differences in the prevalence of OSAS among COPD subjects (14.0\%) and those without COPD (18.6\%) (Sanders et al 2003). In the study by Zamarron and colleagues (2003) of 300 patients referred for clinical suspicion of OSAS, $15.4 \%$ of patients were classified as overlap. More recently, Bednarek and colleagues (2005) studied 356 males and 320 females and found overlap syndrome in $9.2 \%$ of the OSAS population, while O'Brien and Whitman (2005) found overlap syndrome in $11.9 \%$ of COPD patients.

\section{OSAS, COPD, and cardiovascular risk}

Systemic inflammation is increasingly being recognized as a risk factor for a number of different complications including atherosclerosis (Ross 1999) and is a well-established factor in the pathogenesis of cardiovascular disease (CVD) (Hansson 2005). There is growing recognition that COPD is a systemic 


\section{OSAS}

COPD

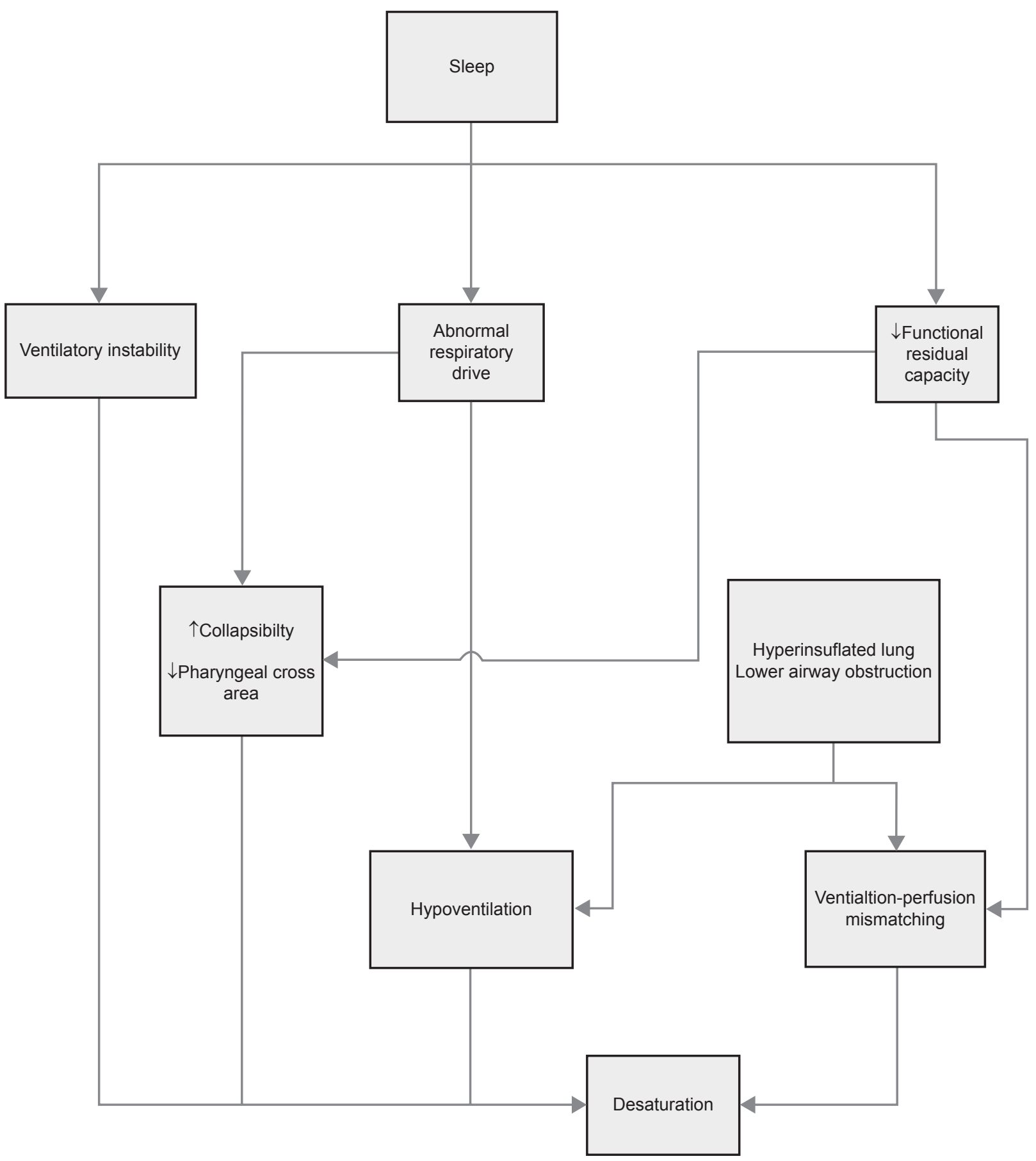

Obesity

Figure I A heuristic model of the complex associations between sleep, COPD and sleep apnea.

Abbreviations: COPD, chronic obstructive pulmonary disease; OSAS, obstructive sleep apnea syndrome. 
Table 2 Prevalence of overlap syndrome in COPD and OSAS patients

\begin{tabular}{lllll}
\hline Authors & Number of patients & Sample & Group & Prevalence \\
\hline Chaouat & 265 & Sleep Laboratory & OSAS & $11 \%$ \\
Resta & 213 & Sleep Laboratory & OSAS & $13.6 \%$ \\
De Miguel & 193 & Sleep Laboratory & OSAS & $28.5 \%$ \\
Sanders & 1132 & General population & COPD & $14 \%$ \\
Zamarrón & 300 & Sleep Laboratory & OSAS & $15.4 \%$ \\
Bednarek & 676 & General population & OSAS & $9.2 \%$ \\
O'Brien & 120 & Sleep Laboratory & OSAS & $11.9 \%$ \\
\hline
\end{tabular}

Abbreviations: COPD, chronic obstructive pulmonary disease; OSAS, obstructive sleep apnea syndrome.

disease (Agusti et al 2003; Yende et al 2006) with multiple effects on end-organs including organs in the cardiovascular system (Camilli et al 1991; Sin and Man 2003). The pathophysiology of how COPD increases cardiovascular risk is largely unknown. Several studies have shown that reduced lung function is associated with an increase in a variety of systemic inflammatory markers (Schols et al 1999; Takabatake et al 2000; Godoy et al 2003). Gan and colleagues (2004) conducted a systematic review of studies involving the relationship between COPD, forced expiratory volume in one second $\left(\mathrm{FEV}_{1}\right)$, and levels of various systemic inflammatory markers. Compared to healthy controls, COPD patients were found to have significantly raised levels of C-reactive protein (CRP), fibrinogen, leucocytes, and tumor necrosis factor-alpha (TNF- $\alpha$ ). All of which indicate persistent systemic inflammation. This finding may explain, at least in part, the high prevalence of systemic complications (including cardiovascular diseases) among patients with COPD (Gan et al 2004).

C-reactive protein is an important serum marker of inflammation and an independent predictor of cardiovascular disease (Rutter et al 2004; Ridker et al 2004). CRP is increased in COPD patients and may be a systemic marker of the inflammatory process (Broekhuizen et al 2006; Man et al 2006; Pinto-Plata et al 2006).

A number of epidemiological studies have shown that OSAS is associated to cardiovascular morbidity (Nieto et al 2000; Peker et al 2002; Becker et al 2003; Marin et al 2005). In this disease, intense local and systemic inflammation occurs. These patients present elevated inflammatory mediators such as TNF- $\alpha$ and interleukin-6 (Liu et al 2000; Carpagnano et al 2002; Imagawa et al 2004; Goldbart et al 2006), leptin (Ip et al 2000; Shimizu et al 2002; Harsch et al 2003; Ozturk et al 2003; Barcelo et al 2005), and adhesion molecules (Ohga et al 1999; Chin et al 2000; El-Solh et al 2002; Dyugovskaya et al 2002; Zamarron-Sanz et al 2006).
The levels of these mediators improve with CPAP treatment (Hatipoglu and Rubinstein 2003; Minoguchi et al 2004).

As in COPD, patients with OSAS present high levels of CRP, which are related to disease severity (Shamsuzzaman et al 2002; Yokoe et al 2003; Kokturk et al 2005; Zouaoui et al 2006).

Endothelial dysfunction is considered an indicator of myocardial or vascular dysfunction before the emergence of clinical signs of overt cardiovascular disease (Celermajer et al 1992). A number of studies involving OSAS patients indicate an associated endothelial dysfunction (Nieto et al 2004; Oflaz et al 2006; Lattimore et al 2006) which improved after CPAP treatment (Ip et al 2004). Few studied, however, have focused on the relation between endothelial dysfunction and COPD. Cella and colleagues (2001) evaluated a variety of plasma markers of endothelial dysfunction in 14 COPD patients, finding altered level of tissue factor pathway inhibitor and selectins.

Furthermore, there is evidence of a perturbed neurohumoral regulatory system in COPD patients (Francis et al 1993; Andreas et al 2005) and OSAS patients (Somers et al 1988; Cortelli et al 1994).

\section{Clinical characteristics}

The most common symptoms of OSAS patients include chronic loud snoring, excessive daytime sleepiness, personality changes, and deterioration of quality of life (Zamarron et al 1998; Redline and Strohl 1998; Pichel et al 2004). COPD patients, on the other hand, may present cough, sputum production, and/or dyspnea (Celli and Mcnee 2004). Nevertheless, overlap patients present unique characteristics, which set them apart from either COPD or OSAS patients.

A number of studies compare the clinical characteristics of overlap patients to those of OSAS-only patients. Chaouat and colleagues (1995) found that, compared to the OSASonly group, the overlap population tended to be older, with more common hypoxemia and hypercapnia, higher mean 
pulmonary artery pressures, but similar body mass index (BMI). O'Brien and Whitman (2005) found that overlap patients were older and less obese. Resta and colleagues (2002) showed that overlap patients had higher $\mathrm{PaCO}_{2}$, as well as similar apnea-hypoapnea index (AHI). This author developed a model for predicting $\mathrm{PaCO}_{2}$ in overlap patients based on $\mathrm{PaO}_{2}, \mathrm{FEV}_{1}$, and weight. However, overlap patients need not be distinctive in all variables. For example, studies by Radwan and colleagues (1995) and Zamarron and colleagues (2003) found no significant differences in OSAS severity, mean arterial oxygen saturation during sleep, and BMI.

Special notice should be taken of Kessler's (1996) suggestion that in OSAS patients exhibiting permanent pulmonary hypertension, bronchial obstruction is generally not severe and the level of hypoxemia and hypercapnia is modest. Therefore, chronic airway obstruction in these patients may be asymptomatic, making it necessary to systematically perform pulmonary function tests in all patients diagnosed with OSAS by polysomnography (Kessler et al 1996).

\section{Quality of sleep}

There is evidence that insomnia and other sleep problems are increased in patients with COPD (Cormick et al 1986). Particularly in elderly COPD patients, sleep quality is decreased in the form of morning tiredness and early awakenings (Bellia et al 2003). In addition, data from sleep studies has shown marked increases in stage changes, frequent arousals and awakenings, long sleep latency, and reduced sleep efficiency (Fleetham et al 1982, Brezinova et al 1982). All these sleep disturbance are likely to have multifactorial origins. Symptoms or comorbid conditions such as nocturnal cough, wheezing, depression, drugs, sedentary lifestyle, and shortness of breath may also contribute (Weitzenblum and Chaouat 2004).

In OSAS patients, one of the most incapacitating symptoms is excessive daytime somnolence, which results from disrupted sleep or nighttime oxygen desaturation (Colt et al 1991; Seneviratne and Puvanendran 2004). Nevertheless, COPD patients did not have any significant daytime sleepiness, despite feeling somewhat tired (Orr et al 1990; Saaresranta et al 2005).

Sanders and colleagues (2003) have observed that COPDonly patients had minimally perturbed sleep. No significant differences were observed in sleep structure with respect to $\mathrm{FEV}_{1}$. Redline and colleagues (2004), in a community-based study, showed that sleep structure variables did not change in subjects with a history of lung disease. In addition, they found that sleep stage distributions varied in accordance with AHI level.

Poor-quality sleep may also be associated to hypoxemia and increased superficial sleep (Sandek et al 1999).

\section{Diagnostic procedures}

The diagnosis of OSAS should be based on clinical findings and confirmed by a full-night polysomnography, which has traditionally been regarded as the gold standard for diagnosis (Deegan and McNicholas 1996; Flemons 2002; Kushida et al 2005). However, alternatives that are less expensive and time consuming are increasingly becoming popular (Flemons et al 2004; Whitelaw et al 2005) (Figure 2).

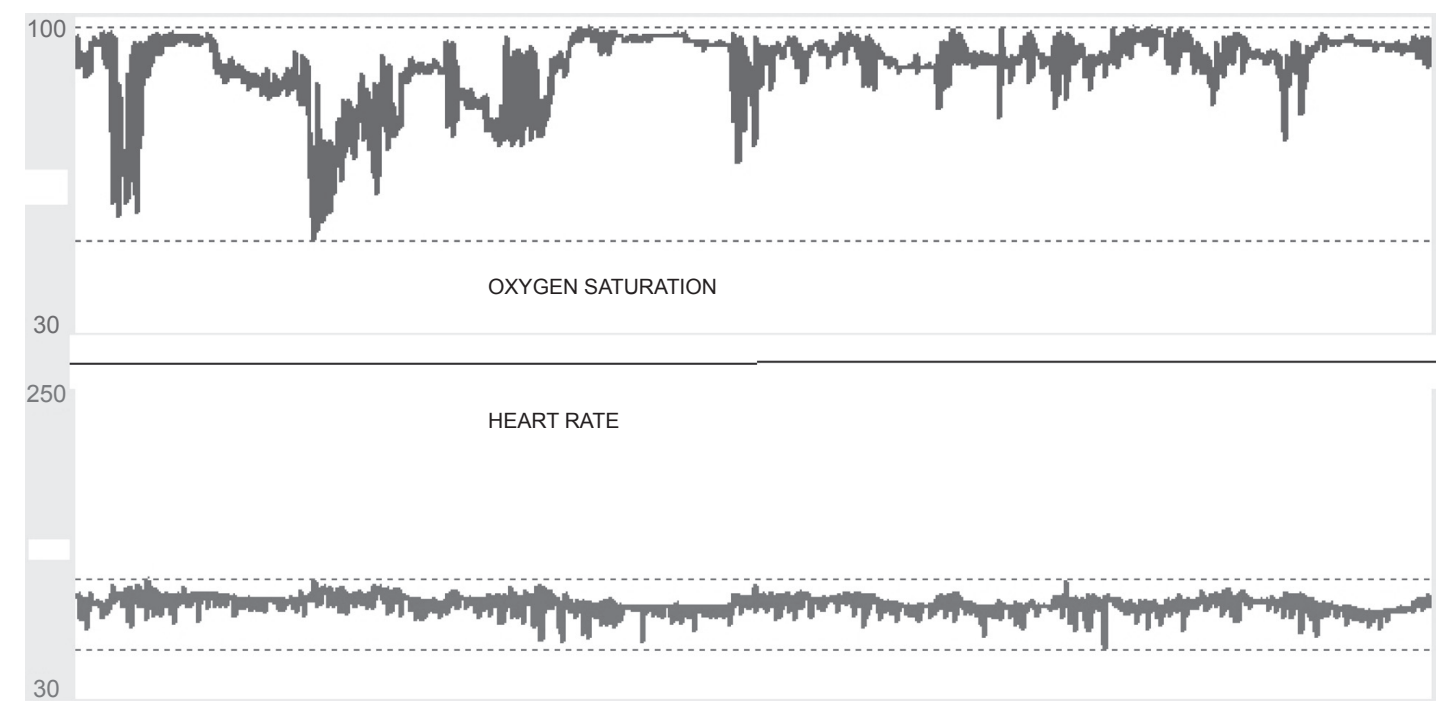

Figure 2 Simultaneous recording of nocturnal oximetry and heart rate in a patient with COPD. Abbreviation: COPD, chronic obstructive pulmonary disease. 
With respect to COPD, clinical assessment should include questions about sleep quality and possible co-existing OSAS. Polysomnography studies are not indicated in COPD except in special circumstances which include a clinical suspicion of OSAS (hypersomnolence), nocturnal hypoxemia complications unexplained by waking arterial oxygen levels, and pulmonary hypertension that is out of proportion to the severity of pulmonary function derangement (Douglas and Flenley 1990).

\section{Treatment}

All patients with OSAS should be counseled about the potential benefits of therapy and the risks of going without therapy. Furthermore, they should be advised of the importance of avoiding factors that increase the severity of upper-airway obstruction such as sleep deprivation, the use of alcohol, hypnotic agents, and increased weight (Loube et al 1994; Haynes 2005). Although CPAP therapy is a well-established, widely used treatment, it is not suitable for all patients (Patel et al 2003; Marshall et al 2006; Giles et al 2006).

Conventional $\mathrm{O}_{2}$ therapy is prescribed to stable COPD patients who exhibit marked and persistent hypoxemia. This therapy is sufficient for correcting even severe nocturnal desaturation and has favorable effects on the observed hypoxemia related peaks of pulmonary hypertension (Fletcher and Levin 1984). Some authors report that oxygen therapy improves the quality of sleep by shortening latency to sleep, increasing REM sleep as well as stages 3 and 4, and by decreasing number of arousals (Goldstein et al 1984, Calverley et al 1982). However, discrepant results exists (Fleetham et al 1982; McKeon et al 1989), which may be due to differences in the severities of daytime and nighttime hypoxemia, as well as study design.

In some patients, particularly those with hypercapnia, higher oxygen flows may induce further carbon dioxide retention with resultant morning headache and confusion. However, if there is a marked worsening in hypercapnia with oxygen therapy, noninvasive nocturnal ventilation (NIPPV) may be added. Although the precise mechanisms are not yet clear, NIPPV could improve gas exchange in COPD patients by resting the respiratory muscles, resetting the respiratory centers (Elliott et al 1991) and improving respiratory mechanics (Simonds et al 1989). Nevertheless, there are conflicting results regarding the utility of this treatment in long-term COPD, particularly during sleep (Wijkstra et al 2003; Ambrosino and Strambi 2004).

Additional treatment options include theophylline, ipratropium bromide tiotropium (Man et al 1996; Martin et al 1999; McNicholas et al 2004).
Certain drugs should be administered with caution. Hypnotics, for example, can adversely affect respiration and gas exchange in patients with COPD by decreasing upper airway muscle tone and blunting the respiratory drive (Steens et al 1993). It is also advisable for COPD patients to avoid alcohol ingestion before sleep because it has been shown to worsen hypoxemia (Easton et al 1987) or lead to hypercapnic respiratory failure (Chan et al 1990).

The coexistence of OSAS and COPD defines a group of special risk patients. In these overlap patients, waking and sleep-related hypoxemia and hypoxemic cardiovascular consequences are more marked than in OSAS-only patients.

CPAP has been shown to acutely improve overnight oxygenation in patients with overlap syndrome. In fact, CPAP with supplemental oxygen for correction of upper airway obstructive episodes and hypoxemia during sleep is the treatment of choice for these patients (Sampol et al 1996).

Few studies exist on the long-term effect of CPAP in overlap syndrome. De Miguel and colleagues (2002) evaluated the effects of CPAP therapy on lung function in patients with overlap syndrome over two consecutive years. After six months of CPAP therapy, there were statistically significant increases in $\mathrm{PaO}_{2}, \mathrm{FEV}_{1}$, and forced vital capacity (FVC). Response of overlap syndrome patients to CPAP therapy was superior in the hypercapnic group, particularly in relation to improvement of arterial blood gases.

Mansfield and Naughton (1999) evaluated the effects of CPAP on lung function in patients with overlap. Fourteen patients were studied, ten of whom were able to tolerate CPAP for at least three months. Improvement was found in gas exchange and $\mathrm{FEV}_{1}$ associated with a decrease in hospitalizations.

CPAP treatment may have other potentially benefits. As COPD is an inflammatory airways disorder, it may be that OSAS acts as an inflammatory stimulus. Thus, the improvement in OSAS resulting from the application of CPAP may, in turn, lead to an improvement in the coexistent COPD. Nevertheless, further study is still needed.

\section{Acknowledgments}

Funding for this study was provided by grants PGIDIT04SIN206003PR and FIS PI051094. The authors report no conflicts of interest in this work.

\section{References}

Agusti AG, Noguera A, Sauleda J, et al. 2003. Systemic effects of chronic obstructive pulmonary disease. Eur Respir J, 21:347-60.

Agusti AG. 2005. COPD, a multicomponent disease: implications for management. Respir Med, 99:670-82. 
Ambrosino N, Strambi S. 2004. New strategies to improve exercise tolerance in chronic obstructive pulmonary disease. Eur Respir J, 24:313-22.

Andreas S, Anker SD, Scanlon PD, et al. 2005. Neurohumoral activation as a link to systemic manifestations of chronic lung disease. Chest, 128:3618-24.

Andreassen H, Vestbo J. 2003. Chronic obstructive pulmonary disease as a systemic disease: an epidemiological perspective. Eur Respir $J$ Suppl, 46:2-4.

Badr MS. 1999. Pathogenesis of obstructive sleep apnea. Prog Cardiovasc Dis, 41:323-30.

Bady E, Achkar A, Pascal S, et al. 2000. Pulmonary arterial hypertension in patients with sleep apnoea syndrome. Thorax, 55:934-9.

Ballard RD, Clover CW, Suh BY. 1995. Influence of sleep on respiratory function in emphysema. Am J Respir Crit Care Med, 151:945-51.

Ballard RD, Irvin CG, Martin RJ, et al. 1990. Influence of sleep on lung volume in asthmatic patients and normal subjects. J Appl Physiol, 68:2034-41.

Barcelo A, Barbe F, Llompart E, et al. 2005. Neuropeptide Y and leptin in patients with obstructive sleep apnea syndrome: role of obesity. Am J Respir Crit Care Med, 171:183-7.

Basner RC, Ringler J, Schwartzstein RM, et al. 1991. Phasic electromyographic activity of the genioglossus increases in normals during slow-wave sleep. Respir Physiol, 83:189-200.

Becker HF, Jerrentrup A, Ploch T, et al. 2003. Effect of nasal continuous positive airway pressure treatment on blood pressure in patients with obstructive sleep apnea. Circulation, 107:68-73.

Becker HF, Piper AJ, Flynn WE, et al. 1999. Breathing during sleep in patients with nocturnal desaturation. Am J Respir Crit Care Med, 159:112-8.

Bednarek M, Plywaczewski R, Jonczak L, et al. 2005. There is no relationship between chronic obstructive pulmonary disease and obstructive sleep apnea syndrome: a population study. Respiration, 72:142-9.

Bellia V, Catalano F, Scichilone N, et al. 2003. Sleep disorders in the elderly with and without chronic airflow obstruction: the SARA study. Sleep, 26:318-23.

Berthon-Jones M, Sullivan CE. 1987. Time course of change in ventilatory response to $\mathrm{CO}_{2}$ with long-term CPAP therapy for obstructive sleep apnea. Am Rev Respir Dis, 135:144-7.

Berthon-Jones M, Sullivan CE. 1984. Ventilation and arousal responses to hypercapnia in normal sleeping humans. J Appl Physiol, 57:59-67.

Block AJ, Boysen PG, Wynne JW, et al. 1979. Sleep apnea, hypopnea and oxygen desaturation in normal subjects. A strong male predominance. N Engl J Med, 300:513-7.

Bonsignore MR, Marrone O, Insalaco G, et al. 1994. The cardiovascular effects of obstructive sleep apnoeas: analysis of pathogenic mechanisms. Eur Respir J, 7:786-805.

Bradley TD. 1992. Right and left ventricular functional impairment and sleep apnea. Clin Chest Med, 13:459-79.

Brezinova V, Catterall JR, Douglas NJ, et al. 1982. Night sleep of patients with chronic ventilatory failure and age matched controls: number and duration of the EEG episodes of intervening wakefulness and drowsiness. Sleep, 5:123-30.

Broekhuizen R, Wouters EF, Creutzberg EC, et al. 2006. Raised CRP levels mark metabolic and functional impairment in advanced COPD. Thorax, 61:17-22.

Bryan AC, Muller NL. 1980. Lung mechanics and gas exchange during sleep. Sleep, 3:401-6.

Calverley PM, Brezinova V, Douglas NJ, et al. 1982. The effect of oxygenation on sleep quality in chronic bronchitis and emphysema. Am Rev Respir Dis, 126:206-10.

Camilli AE, Robbins DR, Lebowitz MD. 1991. Death certificate reporting of confirmed airways obstructive disease. Am J Epidemiol, 133:795-800.

Carpagnano GE, Kharitonov SA, Resta O, et al. 2002. Increased 8 -isoprostane and interleukin-6 in breath condensate of obstructive sleep apnea patients. Chest, 122:1162-7.

Catterall JR, Calverley PM, MacNee W, et al. 1985. Mechanism of transient nocturnal hypoxemia in hypoxic chronic bronchitis and emphysema. J Appl Physiol, 59:1698-703.
Celermajer DS, Sorensen KE, Gooch VM, et al. 1992. Non-invasive detection of endothelial dysfunction in children and adults at risk of atherosclerosis. Lancet, 340:1111-5.

Cella G, Sbarai A, Mazzaro G, et al. 2001. Plasma markers of endothelial dysfunction in chronic obstructive pulmonary disease. Clin Appl Thromb Hemost, 7:205-8.

Celli BR, MacNee W. 2004. Standards for the diagnosis and treatment of patients with COPD: a summary of the ATS/ERS position paper. Eur Respir J, 23:932-46.

Chan CS, Bye PT, Woolcock AJ, et al. 1990. Eucapnia and hypercapnia in patients with chronic airflow limitation. The role of the upper airway. Am Rev Respir Dis, 141:861-5.

Chaouat A, Bugnet AS, Kadaoui N, et al. 2005. Severe pulmonary hypertension and chronic obstructive pulmonary disease. Am J Respir Crit Care Med, 172:189-94.

Chaouat A, Weitzenblum E, Kessler R, et al. 1997. Sleep-related $O_{2}$ desaturation and daytime pulmonary haemodynamics in COPD patients with mild hypoxaemia. Eur Respir J, 10:1730-5.

Chaouat A, Weitzenblum E, Krieger J, et al. 1995. Association of chronic obstructive pulmonary disease and sleep apnea syndrome. Am J Respir Crit Care Med, 151:82-6.

Chaouat A, Weitzenblum E, Krieger J, et al. 1996. Pulmonary hemodynamics in the obstructive sleep apnea syndrome. Results in 220 consecutive patients. Chest, 109:380-6.

Chin K, Nakamura T, Shimizu K, et al. 2000. Effects of nasal continuous positive airway pressure on soluble cell adhesion molecules in patients with obstructive sleep apnea syndrome. Am J Med, 109:562-7.

Clausen JL. 1990. The diagnosis of emphysema, chronic bronchitis, and asthma. Clin Chest Med, 11:405-16.

Colt HG, Haas H, Rich GB. 1991. Hypoxemia vs sleep fragmentation as cause of excessive daytime sleepiness in obstructive sleep apnea. Chest, 100:1542-8.

Cormick W, Olson LG, Hensley MJ, et al. 1986. Nocturnal hypoxaemia and quality of sleep in patients with chronic obstructive lung disease. Thorax, 41:846-54.

Cortelli P, Parchi P, Sforza E, et al. 1994. Cardiovascular autonomic dysfunction in normotensive awake subjects with obstructive sleep apnoea syndrome. Clin Auton Res, 4:57-62.

De Miguel J, Cabello J, Sanchez-Alarcos JM, et al. 2002. Long-term effects of treatment with nasal continuous positive airway pressure on lung function in patients with overlap syndrome. Sleep Breath, 6:3-10.

Deegan PC, McNicholas WT. 1995. Pathophysiology of obstructive sleep apnoea. Eur Respir J, 8:1161-78.

Deegan PC, McNicholas WT. 1996. Predictive value of clinical features for the obstructive sleep apnoea syndrome. Eur Respir J, 9:117-24.

Douglas NJ, Flenley DC. 1990. Breathing during sleep in patients with obstructive lung disease. Am Rev Respir Dis, 141:1055-70.

Douglas NJ, White DP, Pickett CK, et al. 1982a. Respiration during sleep in normal man. Thorax, 37:840-4

Douglas NJ, White DP, Weil JV, et al. 1982b. Hypercapnic ventilatory response in sleeping adults. Am Rev Respir Dis, 126:758-62.

Douglas NJ. 1985. Control of ventilation during sleep. Clin Chest Med, 6:563-75.

Duran J, Esnaola S, Rubio R, et al. 2001. Obstructive sleep apnea-hypopnea and related clinical features in a population-based sample of subjects aged 30 to 70 yr. Am J Respir Crit Care Med, 163:685-9.

Dyugovskaya L, Lavie P, Lavie L. 2002. Increased adhesion molecules expression and production of reactive oxygen species in leukocytes of sleep apnea patients. Am J Respir Crit Care Med, 165:934-9.

Easton PA, West P, Meatherall RC, et al. 1987. The effect of excessive ethanol ingestion on sleep in severe chronic obstructive pulmonary disease. Sleep, 10:224-33.

El Bayadi S, Millman RP, Tishler PV, et al. 1990. A family study of sleep apnea. Anatomic and physiologic interactions. Chest, 98:554-9.

Elliott MW, Mulvey DA, Moxham J, et al. 1991. Domiciliary nocturnal nasal intermittent positive pressure ventilation in COPD: mechanisms underlying changes in arterial blood gas tensions. Eur Respir J, 4:1044-52. 
El-Solh AA, Mador MJ, Sikka P, et al. 2002. Adhesion molecules in patients with coronary artery disease and moderate-to-severe obstructive sleep apnea. Chest, 121:1541-7.

Erbland ML, Ebert RV, Snow SL. 1990. Interaction of hypoxia and hypercapnia on respiratory drive in patients with COPD. Chest, 97:1289-94.

Faulkner MA, Hilleman DE. 2003. Pharmacologic treatment of chronic obstructive pulmonary disease: past, present, and future. Pharmacotherapy, 23:1300-15.

Flenley DC. 1985. Sleep in chronic obstructive lung disease. Clin Chest Med, 6:651-61.

Fleetham J, West P, Mezon B, et al. 1982. Sleep, arousals, and oxygen desaturation in chronic obstructive pulmonary disease. The effect of oxygen therapy. Am Rev Respir Dis, 126:429-33.

Flemons WW, Douglas NJ, Kuna ST, et al. 2004. Access to diagnosis and treatment of patients with suspected sleep apnea. Am J Respir Crit Care Med, 169:668-72.

Flemons WW. 2002. Clinical practice. Obstructive sleep apnea. $N$ Engl J Med, 347:498-504.

Fletcher EC, Levin DC. 1984. Cardiopulmonary hemodynamics during sleep in subjects with chronic obstructive pulmonary disease. The effect of short- and long-term oxygen. Chest, 85:6-14.

Fogel RB, Malhotra A, White DP. 2004. Sleep. 2: pathophysiology of obstructive sleep apnoea/hypopnoea syndrome. Thorax, 59:159-63.

Francis GS, McDonald KM, Cohn JN. 1993. Neurohumoral activation in preclinical heart failure. Remodeling and the potential for intervention. Circulation, 87:90-6.

Gan WQ, Man SF, Senthilselvan A, et al. 2004. Association between chronic obstructive pulmonary disease and systemic inflammation: a systematic review and a meta-analysis. Thorax, 59:574-80.

Garay SM, Rapoport D, Sorkin B, et al. 1981. Regulation of ventilation in the obstructive sleep apnea syndrome. Am Rev Respir Dis, 124:451-7.

Gastaut H, Tassinari CA, Duron B. 1965. Polygraphic study of diurnal and nocturnal (hypnic and respiratory) episodal manifestations of Pickwick syndrome. Rev Neurol (Paris), 112:568-79.

Giles TL, Lasserson TJ, Smith BJ, et al. 2006. Continuous positive airways pressure for obstructive sleep apnoea in adults. Cochrane Database Syst Rev, CD001106.

Godoy I, Campana AO, Geraldo RR, et al. 2003. Cytokines and dietary energy restriction in stable chronic obstructive pulmonary disease patients. Eur Respir J, 22:920-5.

Goldbart AD, Krishna J, Li RC, et al. 2006. Inflammatory mediators in exhaled breath condensate of children with obstructive sleep apnea syndrome. Chest, 130:143-8.

Goldstein RS, Ramcharan V, Bowes G, et al. 1984. Effect of supplemental nocturnal oxygen on gas exchange in patients with severe obstructive lung disease. $N$ Engl J Med, 310:425-9.

Guilleminault C, Cummiskey J, Motta J. 1980. Chronic obstructive airflow disease and sleep studies. Am Rev Respir Dis, 122:397-406.

Guilleminault C, Tilkian A, Dement WC. 1976. The sleep apnea syndromes. Ann Rev Med, 27:465-84.

Guilleminault C. 1985. Obstructive sleep apnea. The clinical syndrome and historical perspective. Med Clin North Am, 69:1187-203.

Hansson GK. 2005. Inflammation, atherosclerosis, and coronary artery disease. $N$ Engl J Med, 352:1685-95.

Harsch IA, Konturek PC, Koebnick C, et al. 2003. Leptin and ghrelin levels in patients with obstructive sleep apnoea: effect of CPAP treatment. Eur Respir J, 22:251-7.

Hatipoglu U, Rubinstein I. 2003. Inflammation and obstructive sleep apnea syndrome pathogenesis: a working hypothesis. Respiration, 70:665-71.

Hawrylkiewicz I, Sliwinski P, Gorecka D, et al. 2004. Pulmonary haemodynamics in patients with OSAS or an overlap syndrome. Monaldi Arch Chest Dis, 61:148-52.

Haynes PL. 2005. The role of behavioral sleep medicine in the assessment and treatment of sleep disordered breathing. Clin Psychol Rev, 25:673-705
Heijdra YF, Dekhuijzen PN, van Herwaarden CL, et al. 1995. Nocturnal saturation and respiratory muscle function in patients with chronic obstructive pulmonary disease. Thorax, 50:610-2.

Hudgel DW, Devadatta P. 1984. Decrease in functional residual capacity during sleep in normal humans. J Appl Physiol, 57:1319-22.

Hudgel DW, Gordon EA, Thanakitcharu S, et al. 1998. Instability of ventilatory control in patients with obstructive sleep apnea. Am J Respir Crit Care Med, 158:1142-9.

Hudgel DW. 1992. Mechanisms of obstructive sleep apnea. Chest, 101:541-9.

Imagawa S, Yamaguchi Y, Ogawa K, et al. 2004. Interleukin-6 and tumor necrosis factor-alpha in patients with obstructive sleep apnea-hypopnea syndrome. Respiration, 71:24-9.

Ip MS, Lam KS, Ho C, et al. 2000. Serum leptin and vascular risk factors in obstructive sleep apnea. Chest, 118:580-6.

Ip MS, Tse HF, Lam B, et al. 2004. Endothelial function in obstructive sleep apnea and response to treatment. Am J Respir Crit Care Med, 169:348-53

Kessler R, Chaouat A, Weitzenblum E, et al. 1996. Pulmonary hypertension in the obstructive sleep apnoea syndrome: prevalence, causes and therapeutic consequences. Eur Respir J, 9:787-94.

Kokturk O, Ciftci TU, Mollarecep E, et al. 2005. Elevated C-reactive protein levels and increased cardiovascular risk in patients with obstructive sleep apnea syndrome. Int Heart J, 46:801-9.

Krimsky WR, Leiter JC. 2005. Physiology of breathing and respiratory control during sleep. Semin Respir Crit Care Med, 26:5-12.

Kushida CA, Littner MR, Morgenthaler T, et al. 2005. Practice parameters for the indications for polysomnography and related procedures: an update for 2005. Sleep, 28:499-521.

Laks L, Lehrhaft B, Grunstein RR, et al. 1995. Pulmonary hypertension in obstructive sleep apnoea. Eur Respir J, 8:537-41.

Lattimore JL, Wilcox I, Skilton M, et al. 2006. Treatment of obstructive sleep apnoea leads to improved microvascular endothelial function in the systemic circulation. Thorax, 61:491-5.

Leech JA, Onal E, Baer P, et al. 1987. Determinants of hypercapnia in occlusive sleep apnea syndrome. Chest, 92:807-13.

Lewis CA, Eaton TE, Fergusson W, et al. 2003. Home overnight pulse oximetry in patients with COPD: more than one recording may be needed. Chest, 123:1127-33.

Liistro G. 2002. Pathophysiology of upper airway obstruction during sleep. Acta Otorhinolaryngol Belg, 56:101-6.

Lin CC. 1994. Effect of nasal CPAP on ventilatory drive in normocapnic and hypercapnic patients with obstructive sleep apnoea syndrome. Eur Respir J, 7:2005-10.

Lindberg A, Jonsson AC, Ronmark E, et al. 2005. Prevalence of chronic obstructive pulmonary disease according to BTS, ERS, GOLD and ATS criteria in relation to doctor's diagnosis, symptoms, age, gender, and smoking habits. Respiration, 72:471-9.

Lindstrom M, Jonsson E, Larsson K, et al. 2002. Underdiagnosis of chronic obstructive pulmonary disease in Northern Sweden. Int J Tuberc Lung Dis, 6:76-84

Liu H, Liu J, Xiong S, et al. 2000. The change of interleukin-6 and tumor necrosis factor in patients with obstructive sleep apnea syndrome. J Tongji Med Univ, 20:200-2.

Loube DI, Loube AA, Mitler MM. 1994. Weight loss for obstructive sleep apnea: the optimal therapy for obese patients. J Am Diet Assoc, 94:1291-5.

Louw SJ, Goldin JG, Joubert G. 1996. Spirometry of healthy adult South African men. Part I. Normative values. S Afr Med J, 86:814-9.

Lugaresi E, Coccagna G, Mantovani M, et al. 1972. Some periodic phenomena arising during drowsiness and sleep in man. Electroencephalogr Clin Neurophysiol, 32:701-5.

Man GC, Champman KR, Ali SH, et al. 1996. Sleep quality and nocturnal respiratory function with once-daily theophylline (Uniphyl) and inhaled salbutamol in patients with COPD. Chest, 110:648-53.

Man SF, Connett JE, Anthonisen NR, et al. 2006. C-reactive protein and mortality in mild to moderate chronic obstructive pulmonary disease. Thorax, 61:849-53. 
Mansfield D, Naughton MT. 1999. Effects of continuous positive airway pressure on lung function in patients with chronic obstructive pulmonary disease and sleep disordered breathing. Respirology, 4:365-70.

Marin JM, Carrizo SJ, Vicente E, et al. 2005. Long-term cardiovascular outcomes in men with obstructive sleep apnoea-hypopnoea with or without treatment with continuous positive airway pressure: an observational study. Lancet, 365:1046-53.

Marshall NS, Barnes M, Travier N, et al. 2006. Continuous positive airway pressure reduces daytime sleepiness in mild to moderate obstructive sleep apnoea: a meta-analysis. Thorax, 61:430-4.

Martin RJ, Bartelson BL, Smith P, et al. 1999. Effect of ipratropium bromide treatment on oxygen saturation and sleep quality in COPD. Chest, 115:1338-45.

McKeon JL, Murree-Allen K, Saunders NA. 1989. Supplemental oxygen and quality of sleep in patients with chronic obstructive lung disease. Thorax, 44:184-8.

McNicholas WT, Calverley PM, Lee A, et al. 2004. Long-acting inhaled anticholinergic therapy improves sleeping oxygen saturation in COPD. Eur Respir J, 23:825-31.

Millman RP, Knight H, Kline LR, et al. 1988. Changes in compartmental ventilation in association with eye movements during REM sleep. J Appl Physiol, 65:1196-202.

Minoguchi K, Tazaki T, Yokoe T, et al. 2004. Elevated production of tumor necrosis factor-alpha by monocytes in patients with obstructive sleep apnea syndrome. Chest, 126:1473-9.

Morrell MJ, Harty HR, Adams L, et al. 1995. Changes in total pulmonary resistance and $\mathrm{PCO} 2$ between wakefulness and sleep in normal human subjects. J Appl Physiol, 78:1339-49.

Muller NL, Francis PW, Gurwitz D, et al. 1980. Mechanism of hemoglobin desaturation during rapid-eye-movement sleep in normal subjects and in patients with cystic fibrosis. Am Rev Respir Dis, 121:463-9.

Mulloy E, McNicholas WT. 1996. Ventilation and gas exchange during sleep and exercise in severe COPD. Chest, 109:387-94.

Nieto FJ, Herrington DM, Redline S, et al. 2004. Sleep apnea and markers of vascular endothelial function in a large community sample of older adults. Am J Respir Crit Care Med, 169:354-60.

Nieto FJ, Young TB, Lind BK, et al. 2000. Association of sleep-disordered breathing, sleep apnea, and hypertension in a large community-based study. Sleep Heart Health Study. JAMA, 283:1829-36.

O'Brien A, Whitman K. 2005. Lack of benefit of continuous positive airway pressure on lung function in patients with overlap syndrome. Lung, 183:389-404.

Oflaz H, Cuhadaroglu C, Pamukcu B, et al. 2006. Endothelial function in patients with obstructive sleep apnea syndrome but without hypertension. Respiration, 73:751-56

Ohga E, Nagase T, Tomita T, et al. 1999. Increased levels of circulating ICAM-1, VCAM-1, and L-selectin in obstructive sleep apnea syndrome. $J$ Appl Physiol, 87:10-4.

Orr WC, Shamma-Othman Z, Levin D, et al. 1990. Persistent hypoxemia and excessive daytime sleepiness in chronic obstructive pulmonary disease (COPD). Chest, 97:583-5.

Ozturk L, Unal M, Tamer L, et al. 2003. The association of the severity of obstructive sleep apnea with plasma leptin levels. Arch Otolaryngol Head Neck Surg, 129:538-40.

Patel SR, White DP, Malhotra A, et al. 2003. Continuous positive airway pressure therapy for treating sleepiness in a diverse population with obstructive sleep apnea: results of a meta-analysis. Arch Intern Med, 163:565-71.

Pauwels RA, Buist AS, Ma P, et al. 2001. Global strategy for the diagnosis, management, and prevention of chronic obstructive pulmonary disease: National Heart, Lung, and Blood Institute and World Health Organization Global Initiative for Chronic Obstructive Lung Disease (GOLD): executive summary. Respir Care, 46:798-825.

Peker Y, Hedner J, Norum J, et al. 2002. Increased incidence of cardiovascular disease in middle-aged men with obstructive sleep apnea: a 7-year follow-up. Am J Respir Crit Care Med, 166:159-65.
Peña VS, Miravitlles M, Gabriel R, et al. 2000. Geographic variations in prevalence and underdiagnosis of COPD: results of the IBERPOC multicentre epidemiological study. Chest, 118:981-9.

Phillipson EA. 1978. Control of breathing during sleep. Am Rev Respir Dis, 118:909-39.

Pichel F, Zamarron C, Magan F, et al. 2004. Health-related quality of life in patients with obstructive sleep apnea: effects of long-term positive airway pressure treatment. Respir Med, 98:968-76.

Pinto-Plata VM, Mullerova H, Toso JF, et al. 2006. C-reactive protein in patients with COPD, control smokers and non-smokers. Thorax, 61:23-8.

Radwan L, Maszczyk Z, Koziorowski A, et al. 1995. Control of breathing in obstructive sleep apnoea and in patients with the overlap syndrome. Eur Respir J, 8:542-5.

Ramsey SD, Sullivan SD. 2003. The burden of illness and economic evaluation for COPD. Eur Respir J Suppl, 41:29-35.

Redline S, Kirchner HL, Quan SF, et al. 2004. The effects of age, sex, ethnicity, and sleep-disordered breathing on sleep architecture. Arch Intern Med, 164:406-18.

Redline S, Leitner J, Arnold J, et al. 1997. Ventilatory-control abnormalities in familial sleep apnea. Am J Respir Crit Care Med, 156:155-60.

Redline S, Strohl KP. 1998. Recognition and consequences of obstructive sleep apnea hypopnea syndrome. Clin Chest Med, 19:1-19.

Resta O, Foschino-Barbaro MP, Bonfitto P, et al. 2000. Prevalence and mechanisms of diurnal hypercapnia in a sample of morbidly obese subjects with obstructive sleep apnoea. Respir Med, 94:240-6.

Ridker PM, Wilson PW, Grundy SM. 2004. Should C-reactive protein be added to metabolic syndrome and to assessment of global cardiovascular risk? Circulation, 109:2818-25.

Ross R. 1999. Atherosclerosis--an inflammatory disease. N Engl J Med, 340:115-26.

Rutter MK, Meigs JB, Sullivan LM, et al. 2004. C-reactive protein, the metabolic syndrome, and prediction of cardiovascular events in the Framingham Offspring Study. Circulation, 110:380-5.

Saaresranta T, Irjala K, Aittokallio T, et al. 2005. Sleep quality, daytime sleepiness and fasting insulin levels in women with chronic obstructive pulmonary disease. Respir Med, 99:856-63.

Sajkov D, Wang T, Saunders NA, et al. 1999. Daytime pulmonary hemodynamics in patients with obstructive sleep apnea without lung disease. Am J Respir Crit Care Med, 159:1518-26.

Sampol G, Sagales MT, Roca A, et al. 1996. Nasal continuous positive airway pressure with supplemental oxygen in coexistent sleep apnoeahypopnoea syndrome and severe chronic obstructive pulmonary disease. Eur Respir J, 9:111-6.

Sandek K, Andersson T, Bratel T, et al. 1999. Sleep quality, carbon dioxide responsiveness and hypoxaemic patterns in nocturnal hypoxaemia due to chronic obstructive pulmonary disease (COPD) without daytime hypoxaemia. Respir Med, 93:79-87.

Sanders MH, Newman AB, Haggerty CL, et al. 2003. Sleep and sleepdisordered breathing in adults with predominantly mild obstructive airway disease. Am J Respir Crit Care Med, 167:7-14.

Sanner BM, Doberauer C, Konermann M, et al. 1997. Pulmonary hypertension in patients with obstructive sleep apnea syndrome. Arch Intern Med, 157:2483-7.

Schols AM, Creutzberg EC, Buurman WA, et al. 1999. Plasma leptin is related to proinflammatory status and dietary intake in patients with chronic obstructive pulmonary disease. Am J Respir Crit Care Med, 160:1220-6.

Seneviratne U, Puvanendran K. 2004. Excessive daytime sleepiness in obstructive sleep apnea: prevalence, severity, and predictors. Sleep Med, 5:339-43.

Series F, Cormier Y, Desmeules M, et al. 1989. Effects of respiratory drive on upper airways in sleep apnea patients and normal subjects. $J$ Appl Physiol, 67:973-9.

Shamsuzzaman AS, Winnicki M, Lanfranchi P, et al. 2002. Elevated C-reactive protein in patients with obstructive sleep apnea. Circulation, $105: 2462-4$ 
Shimizu K, Chin K, Nakamura T, et al. 2002. Plasma leptin levels and cardiac sympathetic function in patients with obstructive sleep apnoeahypopnoea syndrome. Thorax, 57:429-34.

Simonds AK, Parker RA, Branthwaite MA. 1989. The effect of intermittent positive-pressure hyperinflation in restrictive chest wall disease. Respiration, 55:136-43.

Sin DD, Man SF. 2003. Why are patients with chronic obstructive pulmonary disease at increased risk of cardiovascular diseases? The potential role of systemic inflammation in chronic obstructive pulmonary disease. Circulation, 107:1514-9.

Somers VK, Mark AL, Abboud FM. 1988. Sympathetic activation by hypoxia and hypercapnia--implications for sleep apnea. Clin Exp Hypertens A, 10:413-22.

Soto Campos JG, Cano GS, Fernandez GJ, et al. 1996. Hypercapnic stimulation and ventilation response in the syndrome of sleep obstructive apnea. Comparison of reinhalation and steady state. Arch Bronconeumol, 32:341-7.

Steens RD, Pouliot Z, Millar TW, et al. 1993.Effects of zolpidem and triazolam on sleep and respiration in mild to moderate chronic obstructive pulmonary disease. Sleep, 16:318-26.

Takabatake N, Nakamura H, Abe S, et al. 2000. The relationship between chronic hypoxemia and activation of the tumor necrosis factor-alpha system in patients with chronic obstructive pulmonary disease. Am J Respir Crit Care Med, 161:1179-84.

Tangel DJ, Mezzanotte WS, Sandberg EJ, et al. 1992. Influences of NREM sleep on the activity of tonic vs inspiratory phasic muscles in normal men. J Appl Physiol, 73:1058-66.

Tatsumi K, Kimura H, Kunitomo F, et al. 1986. Sleep arterial oxygen desaturation and chemical control of breathing during wakefulness in COPD. Chest, 90:68-73.

Weitzenblum E, Chaouat A. 2004. Sleep and chronic obstructive pulmonary disease. Sleep Med Rev, 8:281-94.

Wellman A, Jordan AS, Malhotra A, et al. 2004. Ventilatory control and airway anatomy in obstructive sleep apnea. Am J Respir Crit Care Med, 170:1225-32.

White DP, Weil JV, Zwillich CW. 1985. Metabolic rate and breathing during sleep. J Appl Physio, 59:384-91.

Whitelaw WA, Brant RF, Flemons WW. 2005. Clinical usefulness of home oximetry compared with polysomnography for assessment of sleep apnea. Am J Respir Crit Care Med, 171:188-93.

Wiegand DA, Latz B, Zwillich CW, et al. 1990. Geniohyoid muscle activity in normal men during wakefulness and sleep. J Appl Physiol, 69:1262-9.
Wiegand L, Zwillich CW, Wiegand D, et al. 1991. Changes in upper airway muscle activation and ventilation during phasic REM sleep in normal men. J Appl Physiol, 71:488-97.

Wiegand L, Zwillich CW. 1994. Obstructive sleep apnea. Dis Mon, 40:197-252.

Wiegand L. 1990. Sleep and resistive loading influences on human upper airway collapsibility. Prog Clin Biol Res, 345:157-66.

Wijkstra PJ, Lacasse Y, Guyatt GH, et al. 2003. A meta-analysis of nocturnal noninvasive positive pressure ventilation in patients with stable COPD. Chest, 124:337-43.

Wright JL, Levy RD, Churg A. 2005. Pulmonary hypertension in chronic obstructive pulmonary disease: current theories of pathogenesis and their implications for treatment. Thorax, 60:605-9.

Yende S, Waterer GW, Tolley EA, et al. 2006. Inflammatory markers are associated with ventilatory limitation and muscle dysfunction in obstructive lung disease in well functioning elderly subjects. Thorax, 61:10-6.

Yokoe T, Minoguchi K, Matsuo H, et al. 2003. Elevated levels of C-reactive protein and interleukin- 6 in patients with obstructive sleep apnea syndrome are decreased by nasal continuous positive airway pressure. Circulation, 107:1129-34.

Younes M, Ostrowski M, Thompson W, et al. 2001. Chemical control stability in patients with obstructive sleep apnea. Am J Respir Crit Care Med, 163:1181-90.

Young T, Palta M, Dempsey J, et al. 1993. The occurrence of sleep-disordered breathing among middle-aged adults. $N$ Engl J Med, 328:1230-5.

Zamarron C, Gude F, Barcala J, et al. 2003. Utility of oxygen saturation and heart rate spectral analysis obtained from pulse oximetric recordings in the diagnosis of sleep apnea syndrome. Chest, 123:1567-76.

Zamarron C, Gude F, Otero Y, et al. 1998. Symptoms of sleep apnea syndrome in the general population. Arch Bronconeumol, 34:245-9.

Zamarron C, Gude F, Otero Y, et al. 1999. Prevalence of sleep disordered breathing and sleep apnea in 50- to 70-year-old individuals. A survey. Respiration, 66:317-22.

Zamarron-Sanz C, Ricoy-Galbaldon J, Gude-Sampedro F, et al. 2006. Plasma levels of vascular endothelial markers in obstructive sleep apnea. Arch Med Res, 37:552-5.

Zouaoui BK, Van MA, Doumit S, et al. 2006. Sleep apnoea-hypopnoea index is an independent predictor of high-sensitivity $\mathrm{C}$-reactive protein elevation. Respiration, 73:243-6. 